\title{
Behaviour of Tourists towards Conserving Underwater Cultural Heritage
}

\author{
Mehuli Bhadra* and Nagarjuna $\mathrm{G}^{\dagger}$
}

\begin{abstract}
Culture and heritage are some of the pull factors that attract tourists towards the destination. Visiting landbased culture and heritage sites is quite common among tourists. Under the culture and heritage tag, underwater cultural water is getting more attention from the tourists since it gives a different, memorable and adventure experience. Underwater cultural heritage is nothing but traces of human existence having a cultural, historical and archaeological character which have been partially or underwater. It is essential to conserve and preserve the underwater cultural heritage since it holds the importance of past culture and tradition of humans. The main objective of the study is to find out tourists' awareness and the importance of preserving underwater cultural heritage. The area of the study covers Gujarat and Tamil Nadu since each destination holds significant underwater cultural heritage value in India. The recommendations of the study will be useful to promote India has one of the prominent underwater cultural heritage destinations.
\end{abstract}

Keywords: Conservation, archaeological, underwater cultural heritage, Destination

\footnotetext{
* BBA (Tourism and Travel Management), BGR Campus, Christ (Deemed to be )University, Bangalore, India: mehuli.bhadra@bba.christuniversity.in † Assistant Professor, School of Business and Management, Christ (Deemed to be) University, BGR Campus, Bangalore, India; nagarjuna.g@christuniversity.in; ORCID ID: https://orcid.org/00000002-5908-1883
} 


\section{Introduction}

Underwater cultural heritage" means all traces of human existence having a cultural, historical or archaeological character which has been partially or underwater, periodically or continuously, for at least 100 years such as i. sites, structures, buildings, artefacts and human remains, together with their archaeological and natural context; ii. vessels, aircraft, other vehicles or any part thereof, their cargo or other contents, together with their archaeological and natural context; and iii. Objects of prehistoric character. iv. Pipelines and cables placed on the seabed shall not be considered as underwater cultural heritage. v. Installations other than pipelines and cables, placed on the seabed and still in use, shall not be considered as underwater cultural heritage. Underwater Cultural Heritage (UCH) plays a vital role in scientific research and education. They help in understanding the development of human civilisation. Artefacts like shipwrecks, war memorials provide vital facts on past cultural interchanges, trade and mutual influences. Sunken cities dwellings and religious sites will provide data on local life religious ceremonies and local life. Apart from providing vital information, these submerged assets provide an opportunity for sustainable development recreation urban development and the cultural enrichment of the surrounding area. It also provides opportunities for cultural and recreational activity as well as tourism development. The revenue generated from these activities can be used as an investment to protect and preserve these monuments. Additionally, it increases consideration for heritage and a sense of pride among the local community (UNESCO, 2001).

\section{Underwater cultural heritage around the world}

Some of the examples of underwater cultural heritage (Land-Based and in Situ with help of Dive Tourism) are highlighted in the below-mentioned table that illustrates the benefits of submerged assets to the society in terms of cultural, educational and sustainable development. 
Table 1: Underwater Cultural Heritage around the world

\begin{tabular}{ll}
\hline Name of the Country & \multicolumn{1}{c}{ Land-Based Underwater Cultural Heritage } \\
\hline China & Maritime Silk Road Museum \\
Canada/ Spain & San Juan Wreck \\
Germany & Haithabu \\
Denmark & Viking Ship Museum \\
Egypt & Alexandria underwater Museum Project, \\
Sweden & Vasa Museum \\
Spain & National Museum of Underwater Archaeology \\
& ARQUA \\
Turkey & Bodrum Museum \\
UK & Mary Rose Museum \\
USA & Great Lake Maritime Museum \\
\hline & \multicolumn{1}{c}{ In Situ Underwater Cultural Heritage } \\
\hline Australia & Yongala \\
Federal States of & Chuuk Lagoon \\
Micronesia & \\
Egypt & Alexandria Eastern Harbour \\
Grenada & Shipwreck Diving \\
UK & Scapa Flow, Scylla and Stirling castle Wrecks \\
USA & Thunder Bay National Marine Sanctuary and \\
USA & Great Lakes Maritime Center, Michigan \\
\hline
\end{tabular}

Source: United Nations Educational Scientific and Cultural Organization, 2001

\section{Underwater Cultural Heritage in India}

India is known for its built world heritage sites and vibrant living traditions of the country. There are several challenges in terms of getting recognition of maritime heritage such as lack of legislations, looting, commercial exploitations, natural disasters and climate change impact. The government of India launched 'Project Mausam' in the year 2014 to enhance its initiative for the conservation of underwater cultural heritage and to create wider awareness about the importance of underwater cultural heritage (Falt, 2020).

The two major recognised underwater cultural heritage sites in India are Mahabalipuram and Dwarka. Mahabalipuram, UNESCO World Heritage is located on the Tamil Nadu coast of India. After 
the tsunami in the year 2004, the area revealed the presence of underwater archaeological remains (UNESCO). The underwater archaeological exploration revealed many structural remains including fallen walls, scattered dresses stone blocks, a few steps leading to a platform. Due to strong underwater currents and swells the structures were damaged and scattered (Sundaresh, Gaur et al, 2004). Dwarka in Gujarat is an ancient harbour as well as one of the major religious centres of Hindus in India. During explorations, a large number of stone structures which appears to be the remains of ancient jetty and stone anchors of various types are discovered in Dwarka waters. This indicates the Dwarka was an important port since historical times. There is a belief that flourishing port and religious capital submerged under the sea after the death of Lord Krishna (Gaur, Sundaresh \& Tripati, 2004).

India has to consider In-situ protection of the underwater cultural heritage which is lying underwater to reduce the damage and to retain its context. Designing In-situ museum, trails and tours in glass boats and courses for divers provide ample opportunities for marine adventurers to access and experience such heritage sustainably and responsibly (Falt, 2020).

\section{Review of Literature}

Visitors behave responsibly when they visit heritage buildings and local culture. They express environmental-related concerns about the tourist's surroundings. Visitors would like a memorable cultural heritage experience. Heritage visitors can be segregated into memorable tourism experience seeker, culturally significant, responsible, willingness to pay and green tourists (Teo, Khan \& Rahim, 2014). Underwater cultural heritage gained attention not only from the scientific community but also from the general public. Underwater cultural heritage can be used as a tool to develop leisure diving and tourism. It started attracting many tourists because of the mystery of its location and historical context. The building of an underwater museum and making access to the public is seen as one of the strategies to attract more number of tourists (UNESCO, 2001). Apart from coral reefs and marine life, shipwrecks, aircraft wrecks and other submerged vehicles attract a 
large number of tourists. Though it creates interest among the tourists in the cultural heritage of the battlefields at the same time they can cause damage in terms of vandalism, the act of memorialisation, looting, collecting souvenirs, anchor mooring damage and moving artefacts. So, it is essential to examine the behaviour of the tourists and their attitude towards heritage sites (McKinnon, 2015). There are numerous measures taken by China to protect and preserve the underwater cultural heritage from looting and illegal salvage (Jing, 2017). The diving tourists are attracted by the shipwrecks and marine environment of the underwater cultural heritage. There is a need for effective interpretation by the archaeologist department about the appreciation of underwater cultural heritage as it connects to our past rather than utilising it to attract more number of tourists. It is the responsibility of archaeologists to educate the tourists about the importance of preserving underwater cultural heritage (Scott -Ireton \& McKinnon, 2016). Underwater cultural sites are becoming one of the prominent cultural attraction. Since it's not accessible on-site to the public and a considerable amount of them are made accessible to the average tourists without compromising on its preservation. Underwater cultural heritage may provide long term opportunities for cultural and recreational tourism but at the same, it can cause negative impacts on the site because of the coastal promenade, water pollution and sand recovery to construct new hotels (UNESCO, 2001). Numerous events took place in world war I \& II and that has left historical evidence in terms of shipwrecks, submerged aircraft, and war artefacts as underwater cultural heritage. The sustainable management of these artefacts is incredibly challenging and important. The proper legal framework both from global and local context is essential for the preservation of underwater cultural heritage (Argyropoulos \& Strategia, 2019). The activities undertaken in marine space has grown rapidly due to innovative technology, moving from traditional activities such as navigation and maritime transport, fisheries to new ones in terms of extraction of hydrocarbons, energy production, aquaculture, tourism and leisure, military use and so on. As a result, it not only causes a greater impact on marine natural resources but also on underwater cultural heritage. Though tourism development and 
leisure create economic opportunities, at the same it can also harm underwater cultural heritage because of the direct contacts of the humans in water-based adventure activities (Papageorgiou, 2019). From the global tourism perspective, underwater cultural heritage has gained more popularity and attracting more number of tourists to a destination that is known for its underwater cultural heritage. It is essential to include submerged monuments visits in the tourists itinerary and awareness programs needs to be organised among tour guides and tourists to recognise the importance of this cultural heritage in tourism (EL-Kady, 2017). The preservation of underwater cultural heritage has become one of the prominent issues due to its research and preservation of shipwrecks which has high historical and scientific value. Another important factor is interest among the general public towards underwater cultural heritage calls for its protection, research, security aspects and tourism potential. To address this, Maritime spatial planning can be used as a tool to protect and manage the underwater cultural heritage (Partiseapate, 2013).

\section{Research Methodology}

The main objective of the study is to find out tourists' awareness of preserving underwater cultural heritage. The area of the study covers Gujarat and Tamil Nadu since each destination holds significant underwater cultural heritage value in India. The study is quantitative and employs a descriptive research method. All the tourists who visited the Mahabalipuram and Gujarat (Dwarka) during the field visit constituted the population. Among the population, 200 tourists were selected based on the convenient sampling technique. A structured questionnaire was developed to collect primary data. Descriptive statistics and Spearman correlation test is applied to analyse the data.

\subsection{Analysis and Interpretation}

The data collected was processed and tabulated using Microsoft Excel software. The data collected have been analysed using descriptive statistics, Spearman correlation by using SPSS 21 
version statistical software and the results obtained thereby have been interpreted.

Table 2: Relationship between the importance of preservation of $\mathrm{UCH}$ and impact of $\mathrm{UCH}$ on planning and development of a destination

\section{Correlations}

\begin{tabular}{|c|c|c|c|c|}
\hline & & & $\begin{array}{c}\text { Importance } \\
\text { of } \\
\text { preservatio } \\
\text { n of UCH }\end{array}$ & $\begin{array}{c}\text { Impact of } \\
\text { UCH on } \\
\text { planning and } \\
\text { development }\end{array}$ \\
\hline \multirow{8}{*}{$\begin{array}{l}\text { Spearman' } \\
\text { s rho }\end{array}$} & \multirow{4}{*}{$\begin{array}{l}\text { Importance of } \\
\text { preservation } \\
\text { of UCH }\end{array}$} & Correlation & 1.000 & $.668^{* *}$ \\
\hline & & Coefficient & & \\
\hline & & Sig. (2-tailed) & & .000 \\
\hline & & $\mathrm{N}$ & 200 & 30 \\
\hline & Impact of & Correlation & $.668^{* *}$ & 1.000 \\
\hline & $\mathrm{UCH}$ on & Coefficient & & \\
\hline & planning and & Sig. (2-tailed) & .000 & $\cdot$ \\
\hline & development & $\mathrm{N}$ & 200 & 200 \\
\hline
\end{tabular}

**. Correlation is significant at the 0.01 level (2-tailed).

From the results of the above table, it has been found that a positive relationship was observed between the importance of preservation of $\mathrm{UCH}$ and its conservation is considered an integral part of planning and development of a destination $(r=.668, \mathrm{p}<0.01)$ Hence, the null hypothesis is rejected, and the alternative hypothesis is accepted. It means that there is a significant relationship between the preservation of $\mathrm{UCH}$ and its conservation is considered an integral part of the planning and development of a destination. 
Table 3: Relationship between the importance of preservation of $\mathrm{UCH}$ and indigenous models on public participation in heritage preservation.

\section{Correlations}

\begin{tabular}{|c|c|c|c|c|}
\hline & & & $\begin{array}{c}\text { Importance } \\
\text { of } \\
\text { preservatio } \\
n \text { of } \mathrm{UCH}\end{array}$ & $\begin{array}{c}\text { Indigenous } \\
\text { models on } \\
\text { public } \\
\text { participation in } \\
\text { heritage } \\
\text { preservation }\end{array}$ \\
\hline & $\begin{array}{l}\text { Importance of } \\
\text { preservation of }\end{array}$ & $\begin{array}{l}\text { Correlation } \\
\text { Coefficient }\end{array}$ & 1.000 & $.524^{* *}$ \\
\hline & $\begin{array}{l}\text { preservation of } \\
\text { UCH }\end{array}$ & Sig. (2-tailed) & & .000 \\
\hline Spearman' & & $\mathrm{N}$ & $\begin{array}{l}200 \\
524^{* *}\end{array}$ & 30 \\
\hline s rho & models on public & $\begin{array}{l}\text { Correlation } \\
\text { Coefficient }\end{array}$ & .524 & 1.000 \\
\hline & participation in & Sig. (2-tailed) & .000 & \\
\hline & $\begin{array}{l}\text { heritage } \\
\text { preservation }\end{array}$ & & 200 & 200 \\
\hline
\end{tabular}

**. Correlation is significant at the 0.01 level (2-tailed).

From the results of the above table, it has been found that a positive relationship was observed between the importance of preservation of $\mathrm{UCH}$ and indigenous models on public participation in heritage preservation $(\mathrm{r}=.524, \mathrm{p}<0.01)$ Hence, the null hypothesis is rejected, and the alternative hypothesis is accepted. It means that there is a significant relationship between the preservation of $\mathrm{UCH}$ and indigenous models on public participation in heritage preservation. 
Table 4: Relationship between the importance of preservation of $\mathrm{UCH}$ and Impact on economic and community development

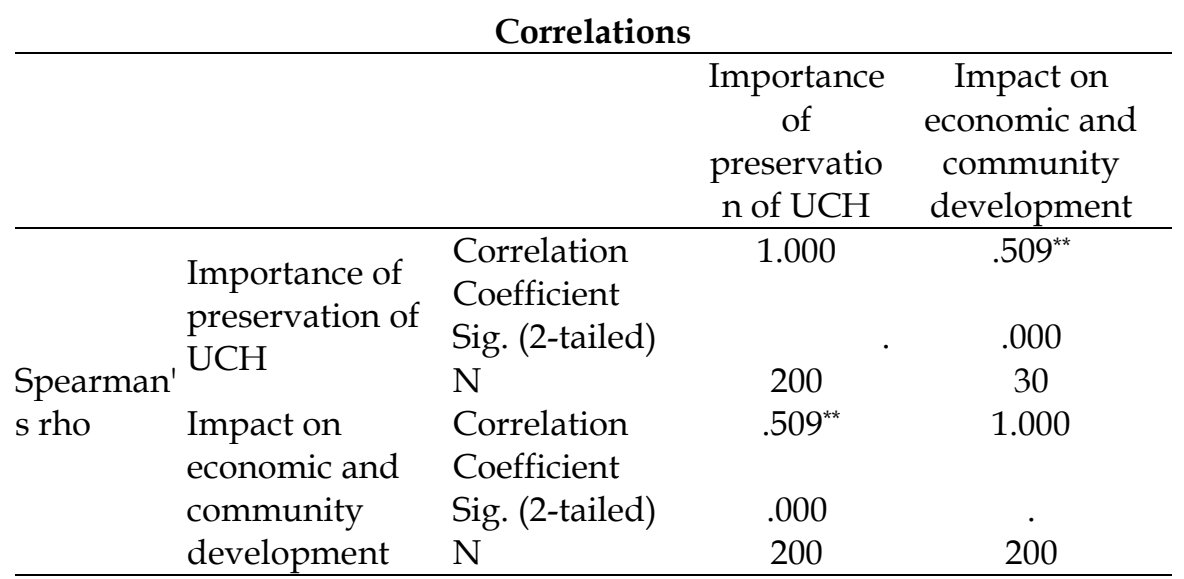

**. Correlation is significant at the 0.01 level (2-tailed).

From the results of the above table, it has been found that a positive relationship was observed between the importance of preservation of $\mathrm{UCH}$ and impact on economic and community development $(\mathrm{r}=.509, \mathrm{p}<0.01)$ Hence, the null hypothesis is rejected, and the alternative hypothesis is accepted. It means that there is a significant relationship between the preservation of $\mathrm{UCH}$ and its impact on economic and community development.

Table 5: Relationship between the importance of preservation of $\mathrm{UCH}$ and Importance given to ruins of historical $\mathrm{UCH}$

\section{Correlations}

\begin{tabular}{|c|c|c|c|c|}
\hline & & & $\begin{array}{c}\text { Importance o } \\
\text { preservation } \\
\text { of } \mathrm{UCH}\end{array}$ & $\begin{array}{l}\text { Importance } \\
\text { given to ruins of } \\
\text { historical } \mathrm{UCH}\end{array}$ \\
\hline & Importance of & Correlation & 1.000 & $.477^{* *}$ \\
\hline & preservation of & $\begin{array}{l}\text { Coefficient } \\
\text { Sig. (2-tailed) }\end{array}$ & & .000 \\
\hline Spearman's & $\mathrm{UCH}$ & $\mathrm{N}$ & 200 & 30 \\
\hline rho & Importance & Correlation & $.477^{* *}$ & 1.000 \\
\hline & given to ruins & Coefficient & & \\
\hline & of historical & Sig. (2-tailed) & .000 & . \\
\hline & $\mathrm{UCH}$ & $\mathrm{N}$ & 200 & 200 \\
\hline
\end{tabular}

**. Correlation is significant at the 0.01 level (2-tailed). 
From the results of the above table, it has been found that a positive relationship was observed between the importance of preservation of $\mathrm{UCH}$ and importance given to ruins of historical $\mathrm{UCH}(\mathrm{r}=.477$, $\mathrm{p}<0.01)$ Hence, the null hypothesis is rejected, and the alternative hypothesis is accepted. It means that there is a significant relationship between the preservation of $\mathrm{UCH}$ and the importance given to the ruins of historical $\mathrm{UCH}$.

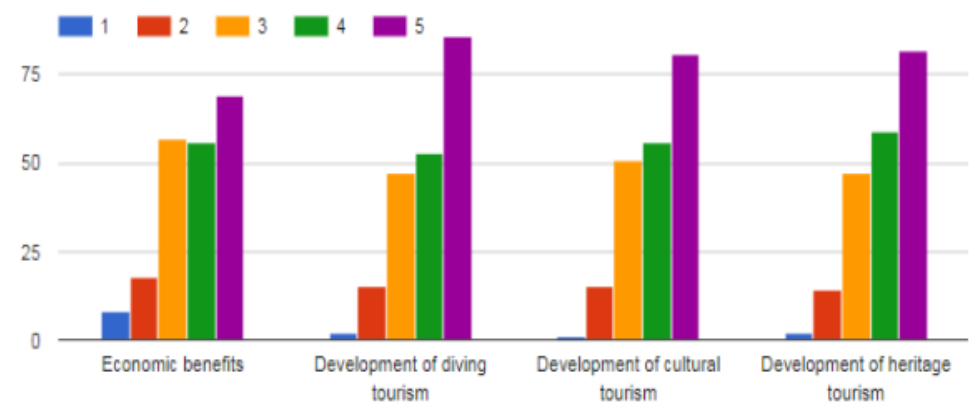

4.1 Figure showing the rating on a scale of 1 to 5 , the scope of developmental aspects of destinations as a result of the conservation of underwater cultural heritage

The variables considered to verify are economic benefits, development of diving tourism, development of cultural tourism, development of heritage tourism, the betterment of maritime museums and development of local tourist accommodation. The survey was conducted, to study a comparative understanding among the variables and which among them holds the highest developmental scope at a destination because of preserving underwater cultural heritage. With the help of the above-given figure, it can be clearly stated that the variable holding the highest scope of development is 'development of diving tourism' as it has received the highest number of ranks 5 by the respondents, followed by the development of heritage tourism, development of cultural tourism, the betterment of maritime museums, development of local tourist accommodation and least developmental aspect being 'economic benefits'. 

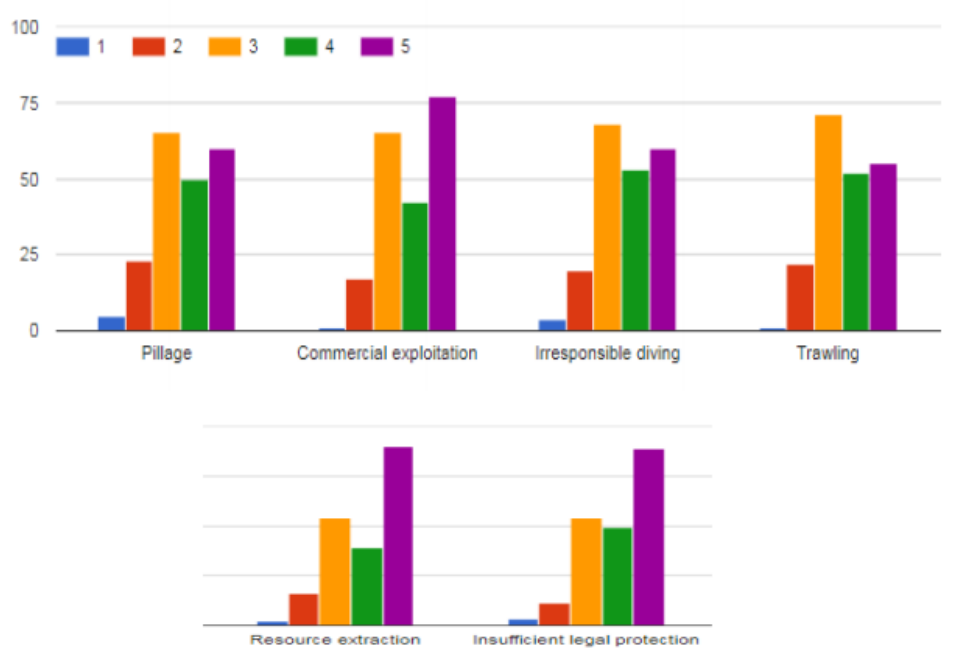

Fig 2: Figure showing the rating on a scale of 1 to 5 of factors that pose the highest amount of threat to the preservation of underwater cultural heritage.

The variables considered to verify are pillage, commercial exploitation, irresponsible diving, trawling, resource extraction and insufficient legal protection. The survey was conducted, to study a comparative understanding among the variables and which among them poses the highest amount of threat towards the preservation of underwater cultural heritage. With the help of the above-given figure, it can be clearly stated that the variable posing the highest amount of threat is 'commercial exploitation as it has received the highest number of ranks 5 by the respondents, followed by resource extraction, insufficient legal protection, irresponsible diving, pillage and the least threat posing factor being 'trawling'.

\section{Findings and Suggestions}

The results of the study indicate that tourists give more importance to the conservation of underwater cultural heritage when they visit the destination. The findings of the study established a positive relationship between the preservation of underwater cultural heritage and its conservation is considered an integral part of planning and development of a destination $(\mathrm{r}=.668, \mathrm{p}<0.01)$, 
indigenous models on public participation in heritage preservation $(\mathrm{r}=.524, \mathrm{p}<0.01)$, impact on economic and community development $(\mathrm{r}=.509, \mathrm{p}<0.01)$ and importance given to ruins of historical $\mathrm{UCH}$ $(\mathrm{r}=.477, \mathrm{p}<0.01)$ respectively. The tourists also believe that the conservation of underwater cultural heritage helps in the promotion and development of dive tourism. According to tourists the major threat to underwater cultural heritage is the commercial exploitation of marine resources.

Based on the findings the study researchers would like to suggest that since tourists are showing interest in dive tourism as well as their concerned towards conservation of submerged assets, coordination among Ministry of Tourism, Ministry of culture and heritage, archaeological department and private stakeholders such as adventure clubs who organise water-based adventure is very much essential to frame sustainable policies and guidelines that not only promote dive tourism and conservation of underwater cultural heritage as well as creating livelihood for local people involving local community members in dive tourism activity. It is essential to adopt the legal framework suggested by UNESCO to protect and preserve the underwater cultural heritage. As of now, India is known for its underwater cultural heritage only in two destinations i.e., Tamil Nadu and Gujarat. So, considering the rich historical facts of India in terms of tradition, religion and culture, there is a possibility of a greater number of hidden underwater cultural heritage. Scientific research and excavation in many coastal areas help in identifying the hidden underwater heritage culture of the country and avoid pressure on a particular destination.

\section{Conclusion}

Underwater cultural heritage provides a unique experience to tourists. The shipwrecks, war memorials and other artefacts of marine resources pull the tourists towards underwater cultural heritage destination. Many countries are investing in infrastructure to create an In-situ museum of underwater cultural heritage since it provides a memorable experience to the tourists. In the year 2001 UNESCO in its convention 'Protection of the Underwater Cultural Heritage' highlighted the importance of conserving underwater 
cultural heritage since it reflects the history and culture of the country. UNESCO also suggested various guidelines and framework protect and preserve the underwater cultural heritage from various negative threats that may harm the underwater cultural heritage. India attracts many foreign tourists because of its rich culture, heritage and tradition in the shape of monuments, festivals, cuisine, archaeological sites. India known for its different religious myths and belief, ancient civilisation and ruled by many kings and dynasties. By keeping this as background, India has a vast scope of doing scientific research in identifying underwater cultural heritage in different parts of the country, creating awareness about the importance of protecting and conserving the underwater cultural heritage and promoting India has one of the prominent underwater cultural heritage destinations both sustainably and economically.

\section{References}

Argyropoulos, V and Strategia, A. (2019). Sustainable management of underwater cultural heritage: The route from discovery to engagement-Open issues in the Mediterranean. Heritage, 2. 1588-1613

Chui Teo, C.B., Mohd Khan, N.R. and Abd Rahim, F.H. (2014). Understanding cultural heritage visitors behavior: The case of Melaka as World Heritage City. Social and Behavioral Sciences, 130. 1-10

EL-Kady, M. (2017). Potentials of underwater cultural heritage in tourism from the perspective of tour guiding in Alexandria, Egypt. Journal of Tourism Research, 17(1). 222-237

Falt, E. (2020, September 24). World Maritime Day: India holds incredible underwater riches waiting to be discovered and recognised. The Indian Express. Retrieved from https:// indianexpress.com/article/ lifestyle/ art-and-culture/world-maritime-day-2020-india-holds-incredibleunderwater-riches-waiting-to-be-discovered-recognised-6607411/

Gaur,A.S., Sundaresh, and Tripati, S (2004). An ancient harbour at Dwarka: Study based on the recent underwater explorations. Current Science, 86 (9). 1256-1260

Jing, Y. (2017). Protection of underwater cultural heritage in China: new developments. International Journal of Cultural Policy, 25(6). 756-764 
McKinnon, J.F. (2015). Memorialization, Graffiti and Artifact Movement: A Case Study of Cultural Impacts on WWII Underwater Cultural Heritage in the Commonwealth of the Northern Mariana Islands. Journal of Maritime Archaeology,10. 11-27

Papageorgiou, M. (2019). Stakes and challenges for underwater cultural heritage in the era of blue growth and the role of spatial planning: Implications and prospects in Greece. Heritage, 2. 1060-1069

Partiseapate. (2013). Workshop: Maritime spatial planning as tool for underwater cultural heritage management. http:// www.partiseapate.eu/dialogue/workshop-cultural-heritagetourism/

Scott -Ireton, D.A. and McKinnon, F.J. (2016). As the sand settles: Education and archaeological tourism on underwater cultural heritage. Public Archaeology, 14 (3). 157-171

Sundaresh, Gaur,A.S., Tripati, S and Vora, K,H. (2004). Underwater investigations off Mahabalipuram, Tamil Nadu, India. Current Science, 86 (9). 1231-1237

UNESCO. (2001). The benefits of the protection of underwater cultural heritage for sustainable growth, tourism and urban development. https:// www.scubatravel.co.uk/unesco-underwater-tourism.pdf

UNESCO. (2001). The UNESCO convention on the protection of the underwater cultural heritage.http:// www.unesco.org/ new/ fileadmin/MULTIMEDIA/HQ/CLT/UNDERWATER/pdf/Infokit_e n_Final.pdf

UNESCO. (n.d.). Underwater cultural heritage inscribed on UNESCO's world heritage list. http:// www.unesco.org/ new/en/culture/ themes/underwater-cultural-heritage/museums-and-tourism/ underwater-cultural-heritage-inscribed-on-unescos-world-heritagelist/\#: :text=Relief $\% 20$ of $\%$ 20the $\% 20 \% 22$ Descend $\% 20$ of, presence $\% 20$ of $\%$ 20underwater \%20archaeological\%20remains. 